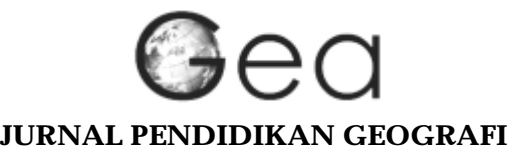

\title{
SISTEM POLA TANAM DI WILAYAH PRIANGAN BERDASAKAN KLASIFIKASI IKLIM OLDEMAN
}

\author{
Akhmad Fadholi ${ }^{1}$, Dina Supriatin ${ }^{2}$ \\ 1'Stasiun Meteorologi Depati Amir Pangkalpinang, akhmad.fadholi@bmkg.go.id \\ 2Stasiun M eteorologi Frans Kaisepo Biak, choki2_miauw @yahoo.co.id
}

\begin{abstract}
Priangan region is the largest food distributor in Indonesia. It has fertile land because there are mountain ranges and river flows. Research on climate conditions of Priangan should be done to determine cropping system in the region. Rainfall is climate element which analyzed in this research because it influences on plant growth directly. It is clear especially in farming areas which required a systematic and simple method to understand the behavior of climate. O Ideman classification system is useful in the classification of agricultural crops in Indonesia by using rainfall element. The criteria are based on the calculation of wet months and the dry season. By using climate classification, Oldeman cropping system can be determined in the region. Based on O Ideman climate classification, most of Priangan region can be classified in climate type B1, B2, $C 1, C 2$ and $C 3$. The wettest climate type in the region is $B 1$, it is suitable to be planted rice short lifespan of 3 (three) times the rice harvest or short life of 2 (two) times the harvest and crops 1 (once) harvests. The driest type is C 3 which fits the short lifespan of cultivated rice 1 (once) and harvest crops 2 (two) times which the second harvest in the dry season.
\end{abstract}

Keyword : rainfall, climate, oldeman climate classification,croppingsystem.

\begin{abstract}
ABSTRAK
Wilayah Priangan merupakan bagian dari Pulau Jawa yang merupakan distributor pangan terbesar di Indonesia. Priangan memiliki tanah yang sangat subur karena di wilayahnya banyak terdapat deretan pegunungan dan sungai yang mengalir. Dengan kondisi topografi yang kompleks ini perlu dilakukan penelitian mengenai kondisi iklimnya untuk menentukan sistem pola tanam di wilayah tersebut. Unsur iklim yang dianalisaadalahunsurcurahhujanyangsangatberperanlangsungterhadap pertumbuhan tanaman dibanding unsur-unsur iklim lainnya. Hal ini tampak nyata terutama pada daerah pesawahan tadah hujan, sehingga diperlukan upaya yang sistematis dan praktis untuk memahami perilaku iklim. Sistem klasifikasi Oldeman sangat berguna dalam klasifikasi Iahan pertanian tanaman pangan di Indonesia dengan menggunakan unsur curah hujan. Kriterianya didasarkan pada perhitungan bulan basah (BB) dan bulan kering (BK) berturut-turut yang batasannya memperhatikan peluang hujan, hujan efektif dan kebutuhan air untuk tanaman. Dengan klasifikasi iklim Oldeman ini dapat ditentukan sistem pola tanam di suatu wilayah. Berdasarkan klasifikasi iklim Oldeman, sebagian besar wilayah Priangan bertipe iklim B1, B2, C1, C2 dan C3. Tipe iklim paling basah di wilayah Priangan adalah tipe B1, yang cocok ditanami padi sawah umur pendek 3 (tiga) kali panen atau padi sawah umur pendek 2 (dua) kali panen dan palawija 1 (satu) kali panen. Sedangkan tipe iklim paling kering di wilayah Priangan adalah tipe C3, yang cocok ditanami padi sawah umur pendek 1 (satu) kali panen dan palawija 2 (dua) kali panen khusus yang kedua jatuh pada musim kemarau.
\end{abstract}

Kata kunci : curah hujan, iklim, klasifikasi iklim ol deman, sistem pola tanam. 


\section{PENDAHULUAN}

\section{Latar Belakang M asalah}

Parahyangan atau Priangan adalah salah satu wilayah di Propinsi Jawa Barat yang wilayahnya mencakup Kabupaten Bandung, Ciamis, Cianjur, Garut, Sukabumi, Sumedang dan Tasikmalaya, yang luasnya mencapai sekitar seperenam Pulau Jawa $( \pm 21.524$ km2) (Susanto, 2002). Bagian Utara Priangan berbatasan dengan Karawang, Purwakarta, Subang, Indramayu, Majalengka dan Kuningan; sebelah Timur dengan Jawa Tengah yang dibatasi oleh sungai Citanduy; sebelah Barat berbatasan dengan Bogor dan lebak serta sebelah Selatan berhadapan dengan Samudera Indonesia. Berikut peta lokasi wilayah Priangan seperti pada Gambar 1.

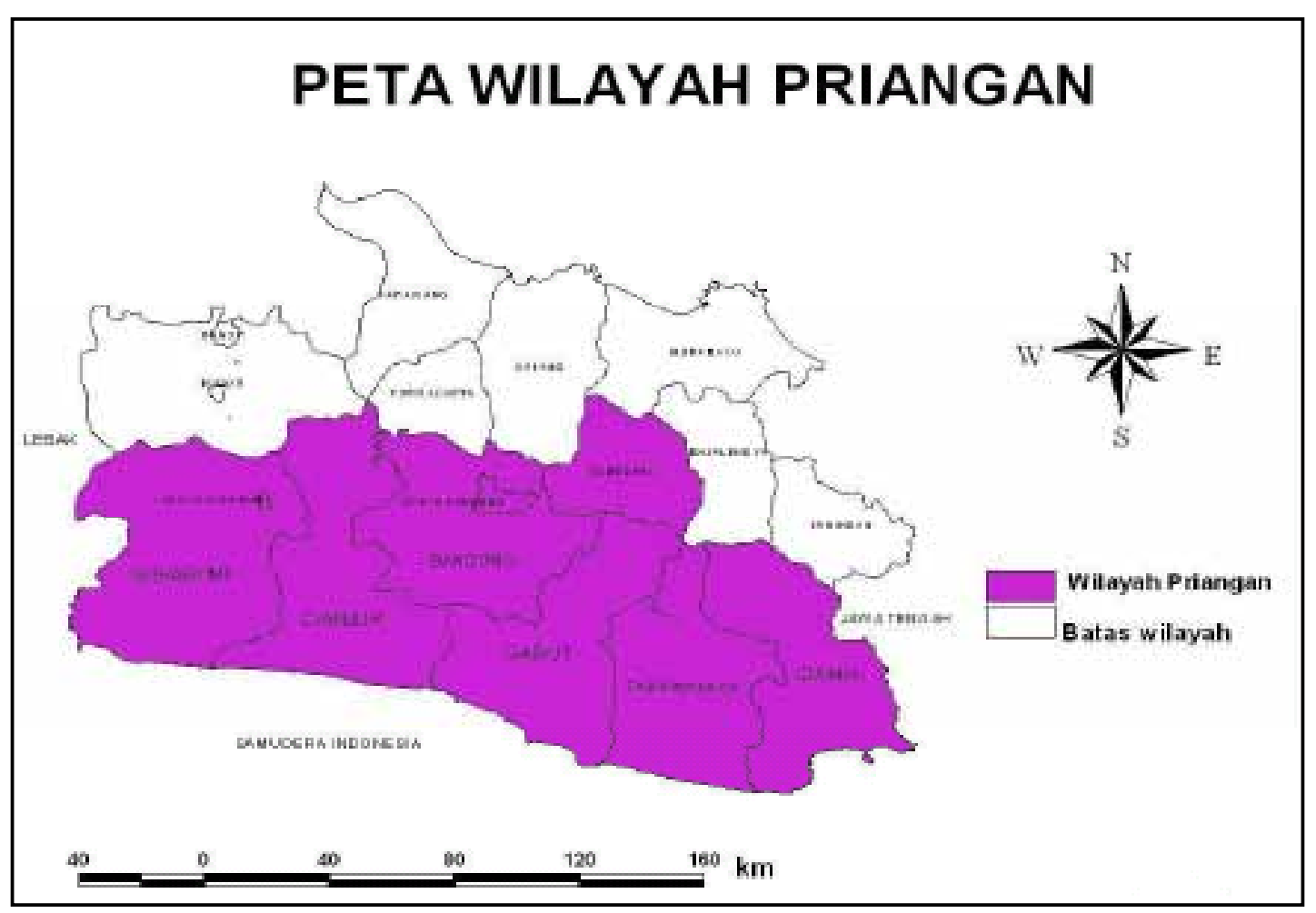

Gambar 1. Peta Wilayah Priangan

Relief tanah daerah Priangan terdiri dari dataran rendah, bukit-bukit dan rangkaian pegunungan, yaitu: Gunung Gede, Gunung Ciremai (termasuk dalam wilayah administratif Majalengka, Kuningan dan Ciamis), Gunung Kancana, Gunung Masigit (Cianjur), Gunung Salak (termasuk dalam wilayah administrative Bogor dan Sukabumi), Gunung Tangkuban Perahu, Gunung Burangrang, Gunung Malabar, Gunung Bukit Tunggul (Bandung), Gunung Tampomas, Gunung Calancang, Gunung Cakra Buana (Sumedang), Gunung Guntur, Gunung Haruman, Gunung Talagabodas, Gunung Karacak, Gunung Galunggung (Garut), Gunung Cupu, Gunung Cula Badak, Gunung Bongkok (Tasi kmalaya), Gunung Syawal (Ciamis). Karena letak geografisnya yang sangat strategis yang dikeliling oleh deretan pegunungan dan terdiri dari banyak sungai menyebabkan wilayah ini menjadi sangat subur dan sangat cocok untuk dijadikan lahan pertanian.

Kegiatan pertanian sangat ditentukan oleh kondisi iklim setempat. Faktor iklim merupakan faktor yang sulit untuk dikendalikan, sehingga iklim menjadi salah satu 
faktor utama yang harus dipertimbangkan dalam menentukan waktu dan pola tanam serta variasi tanaman yang sesuai dengan pola iklim di daerah yang bersangkutan. Penyesuaian tersebut didasarkan pada identifikasi dan pemahaman terhadap kondisi iklim dan kesesuaian lahan yang tepat terhadap komoditas tanaman. Untuk menyesuaikan pola tanam di bidang pertanian dapat dilakukan dengan cara mengenal tipe iklim di suatu wilayah.

Di Indonesia sudah banyak ahli yang membuat tipeklasifikasi iklim di Indonesia, antara lain Schmidth Ferguson (1951), Koppen, Mohr dan Iain-lain yang hampir semuanya didasarkan pada unsur curah hujan. Pulau Jawa merupakan distribusi terbesar bagi sektor pangan di Indonesia. Sedangkan luas wilayah Priangan sebesar seperenam luas wilayah Pulau Jawa. Untuk mengetahui sistem pola tanam di wilayah Priangan maka dilakukan klasifikasi iklim di wilayah tersebut dengan menggunakan metode Oldeman karena cocok untuk komoditas tanaman pangan yaitu padi dan pal awija. Pada metode ini unsur iklim yang dianal isis adalah unsur curah hujan yang sangat berperan langsung terhadap pertumbuhan tanaman dibanding unsur-unsur iklim lainnya. Hal ini tampak nyata terutama pada daerah pesawahan tadah hujan, sehingga diperlukan upaya yang sistematis dan praktis untuk memahami perilaku iklim.

\section{Rumusan masalah}

Daerah Priangan merupakan daerah yang subur dengan topografi yang kompleks yaitu terdiri dari rangkaian pegunungan dan banyak terdapat sungai. Hal ini menyebabkan penulis tertarik untuk meneliti tentang keadaan iklimnya agar dapat menentukan pola tanam di wilayah tersebut.

\section{Tujuan Penelitian}

Tujuan dilakukannya penelitian ini adalah mengklasifikasikan daerah di wilayah Priangan menurut tipeiklim Oldeman serta mengetahui sistem pola tanam di wilayah tersebut.

\section{METODE PENELITIAN}

Penelitian menggunakan data curah hujan bulanan periode 30 tahun (1971-2000) yang diperoleh dari 41 pos hujan yang tersebar di wilayah Priangan, seperti pada Tabel 1. 
Tabel 1. Daftar Nama Stasiun Hujan di Wilayah Priangan yang Diambil Data Hujannya

\begin{tabular}{|c|c|c|c|c|c|}
\hline No & Nama Stasiun & Kabupaten & Lintang & Bujur & Elevai \\
\hline 1 & Pelabuhan Ratu & Sukabumi & -6.98 & 106.55 & 18 \\
\hline 2 & Parakan Salak & Sukabumi & -6.80 & 106.70 & 606 \\
\hline 3 & Cicurug & Sukabumi & -6.93 & 106.47 & 199 \\
\hline 4 & Parungluda & Sukabumi & -6.85 & 106.77 & - \\
\hline 5 & Cisalak (Perk) & Sukabumi & -6.87 & 106.45 & 718 \\
\hline 6 & Pesawahan (Perk) & Sukabumi & -7.13 & 106.62 & 690 \\
\hline 7 & Surade & Sukabumi & -7.33 & 106.57 & 100 \\
\hline 8 & Cipetir & Sukabumi & -6.87 & 106.68 & 265 \\
\hline 9 & Lengkong & Sukabumi & -7.13 & 106.70 & 386 \\
\hline 10 & Mandaling & Sukabumi & -7.00 & 106.78 & 310 \\
\hline 11 & Bojonglopang & Sukabumi & -7.05 & 106.80 & 510 \\
\hline 12 & Goal Para & Sukabumi & -6.85 & 106.97 & 1080 \\
\hline 13 & Dinewati (Perk) & Sukabumi & -7.10 & 106.90 & 580 \\
\hline 14 & Pacet & Cianjur & -6.77 & 107.05 & 1114 \\
\hline 15 & Cikalongkulon & Cianjur & -6.72 & 107.22 & 285 \\
\hline 16 & Vada & Cianjur & -6.73 & 107.18 & 420 \\
\hline 17 & Campaka & Cianjur & -7.03 & 107.13 & 1009 \\
\hline 18 & Pagelaran & Cianjur & -7.22 & 107.13 & 365 \\
\hline 19 & Salatri & Cianjur & -7.42 & 106.90 & 75 \\
\hline 20 & Sindangbarang & Cianjur & -7.45 & 107.13 & 7 \\
\hline 21 & Gunung Halu 2 & Bandung & -7.03 & 107.32 & 1020 \\
\hline 22 & Cibitu & Bandung & -7.22 & 107.37 & 1800 \\
\hline 23 & Cibuni & Bandung & -7.17 & 107.40 & 1260 \\
\hline 24 & Panglejar & Bandung & -7.72 & 107.43 & 600 \\
\hline 25 & Sukawana & Bandung & -6.77 & 107.60 & 1543 \\
\hline 26 & Paseh/Cipalau & & -7.10 & 107.77 & 910 \\
\hline 27 & Cibeureum & Bandung & -7.20 & 107.67 & 560 \\
\hline 28 & Malabar & Bandung & -7.22 & 107.58 & 1550 \\
\hline 29 & Sumedang (DPU) & Sumedang & -6.87 & 107.92 & 465 \\
\hline 30 & Cadasngampar & Sumedang & -6.90 & 108.10 & 230 \\
\hline 31 & Darmaraja & Sumedang & -6.92 & 108.07 & 290 \\
\hline 32 & Tegalkalong & Sumedang & -6.83 & 107.95 & 457 \\
\hline 33 & Tanjungsari 1 & Sumedang & -6.90 & 107.80 & 855 \\
\hline 34 & Malangbong & Garut & -7.07 & 108.08 & 540 \\
\hline 35 & Karangpawitan & Garut & -7.20 & 107.97 & 714 \\
\hline 36 & Cimalaka & Tasikmalaya & -7.73 & 107.93 & 545 \\
\hline 37 & Singaparna & Tasikmalaya & -7.28 & 108.07 & 830 \\
\hline 38 & Pasir Malang & Tasikmalaya & -7.35 & 108.32 & 252 \\
\hline 39 & Panjalu & Ciamis & -7.15 & 108.27 & 790 \\
\hline 40 & Kawali & Ciamis & -7.18 & 108.40 & 300 \\
\hline 41 & Ciamis & Ciamis & -7.33 & 108.35 & 228 \\
\hline
\end{tabular}

Metode yang digunakan dalam penelitian ini antara lain metode statistik sederhana untuk mencari rata-rata curah hujan dan metode interpolasi dalam Sistem Informasi Geografis. 


\section{Rata-rata (mean)}

Metode ini digunakan untuk menghitung nilai rata-rata data yang merupakan nilai yang mewakili data tersebut (Spiegel, 1992):

$\bar{x}=\sum_{i=1}^{n} \frac{x_{i}}{n}$

Keterangan:

$=$ nilai rata-rata

$=$ data ke $-\mathrm{i}$

= banyaknya data

Untuk mempermudah proses perhitungan nilai rata-rata (mean), digunakan software Microsoft Excel 2007.

\section{M etode Sistem Informasi G eografis (SIG)}

Sistem Informasi Geografis (SIG) adalah teknologi untuk menganalisis dan menyimpan informasi geografis berupa sistem perangkat keras dan lunak komputer, data geografis dan personil, yang didesain untuk menghimpun, menyimpan, memperbarui, memanipulasi, menganalisis, dan menampilkan berbagai bentuk informasi dengan referensi geografis. SIG dapat diaplikasikan di berbagai bidang, seperti pertanian, kehutanan, kelautan, perkebunan, industri, pertambangan, iklim dan cuaca, sosial ekonomi, hidrologi, dan sebagainya. Dalam bidang iklim dan cuaca, SIG dapat dimanfaatkan untuk berbagai kebutuhan, seperti pemetaan letak stasiun pengamat cuaca, pemetaan curah hujan wilayah, pemetaan hasil simulasi kesesuaian lahan, pemetaan hasil simulasi software tanaman, penutup/ penggunaan lahan, pemetaan daerah kekeringan atau banjir, dan prakiraan musim atau cuaca. Hasil keluaran sistem informasi geografis, juga dapat digunakan untuk analisis lanjutan. Metode ini digunakan untuk memetakan atau menginterpolasikan daerah pos hujan yang mempunyai kriteria iklim Oldeman yang sama.

\section{HASIL DAN PEMBAHASAN}

Dari hasil pengolahan data curah hujan bulanan wilayah Priangan (41 pos hujan) periode 30 tahun (1971-2000) diperoleh hasil seperti pada Tabel 2. 
Tabel 2. Jumlah Bulan Basah dan Kering serta Tipe Iklim di Tipa Stasiun Hujan

\begin{tabular}{|r|l|l|r|r|l|}
\hline No & \multicolumn{1}{|r|}{ Nama Stasiun } & Kabupaten & $\begin{array}{c}\text { Jumlah } \\
\text { BB }\end{array}$ & $\begin{array}{c}\text { Jumlah } \\
\text { BK }\end{array}$ & $\begin{array}{c}\text { Tipe } \\
\text { Iklim }\end{array}$ \\
\hline 1 & Pelabuhan Ratu & Sukabumi & 6 & 4 & C3 \\
\hline 2 & Parakan Salak & Sukabumi & 8 & 0 & B1 \\
\hline 3 & Cicurug & Sukabumi & 7 & 0 & B1 \\
\hline 4 & Parungkuda & Sukabumi & 8 & 1 & B1 \\
\hline 5 & Cisalak (Perk) & Sukabumi & 7 & 0 & B1 \\
\hline 6 & Pesawahan (Perk) & Sukabumi & 6 & 1 & C1 \\
\hline 7 & Surade & Sukabumi & 6 & 1 & C1 \\
\hline 8 & Cipetir & Sukabumi & 8 & 0 & B1 \\
\hline 9 & Lengkong & Sukabumi & 6 & 1 & C1 \\
\hline 10 & Mandaling & Sukabumi & 7 & 1 & B1 \\
\hline 11 & Bojonglopang & Sukabumi & 7 & 1 & B1 \\
\hline 12 & Goal Para & Sukabumi & 8 & 2 & B2 \\
\hline 13 & Dinewati (Perk) & Sukabumi & 8 & 1 & B1 \\
\hline 14 & Pacet & Cianjur & 8 & 1 & B1 \\
\hline 15 & Cikalongkulon & Cianjur & 6 & 4 & C3 \\
\hline 16 & Vada & Cianjur & 7 & 0 & B1 \\
\hline 17 & Campaka & Cianjur & 7 & 0 & B1 \\
\hline 18 & Pagelaran & Cianjur & 8 & 2 & B2 \\
\hline 19 & Salatri & Cianjur & 5 & 0 & B1 \\
\hline 20 & Sindangbarang & 0 & C1 \\
\hline
\end{tabular}

\begin{tabular}{|l|l|l|r|r|l|}
\hline 21 & Gunung Halu 2 & Bandung & 7 & 0 & B1 \\
\hline 22 & Cibitu & Bandung & 8 & 2 & B2 \\
\hline 23 & Cibuni & Bandung & 8 & 1 & B1 \\
\hline 24 & Panglejar & Bandung & 6 & 3 & C2 \\
\hline 25 & Sukawana & Bandung & 6 & 4 & C3 \\
\hline 26 & Paseh/Cipaku & Bandung & 6 & 4 & C3 \\
\hline 27 & Cibeureum & Bandung & 6 & 3 & C2 \\
\hline 28 & Malabar & Bandung & 6 & 4 & C3 \\
\hline 29 & Tegalkalong & Sumedang & 6 & 4 & C3 \\
\hline 30 & Sumedang (DPU) & Sumedang & 6 & 3 & C2 \\
\hline 31 & Cadasngampar & Sumedang & 6 & 3 & C2 \\
\hline 32 & Darmaraja & Sumedang & 6 & 5 & C3 \\
\hline 33 & Tanjungsari 1 & Sumedang & 6 & 4 & C3 \\
\hline 34 & Malangbong & Garut & 6 & 3 & C2 \\
\hline 35 & Karangpawitan & Garut & 6 & 4 & C3 \\
\hline 36 & Panjalu & Ciamis & 6 & 1 & C1 \\
\hline 37 & Kawali & Ciamis & 8 & 1 & B1 \\
\hline 38 & Ciamis & Ciamis & 8 & 1 & B1 \\
\hline 39 & Singaparna & Tasikmalaya & 7 & 1 & B1 \\
\hline 40 & Cimalaka & Tasikmalaya & 6 & 5 & C3 \\
\hline 41 & Pasir Malang & Tasikmalaya & 6 & 4 & C3 \\
\hline
\end{tabular}


Hasil pengolahan data pada tabel di atas diinterpolasikan pada sebuah peta dengan menggunakan metode SIG (Sistem Informasi Geografis) seperti pada gambar 2.

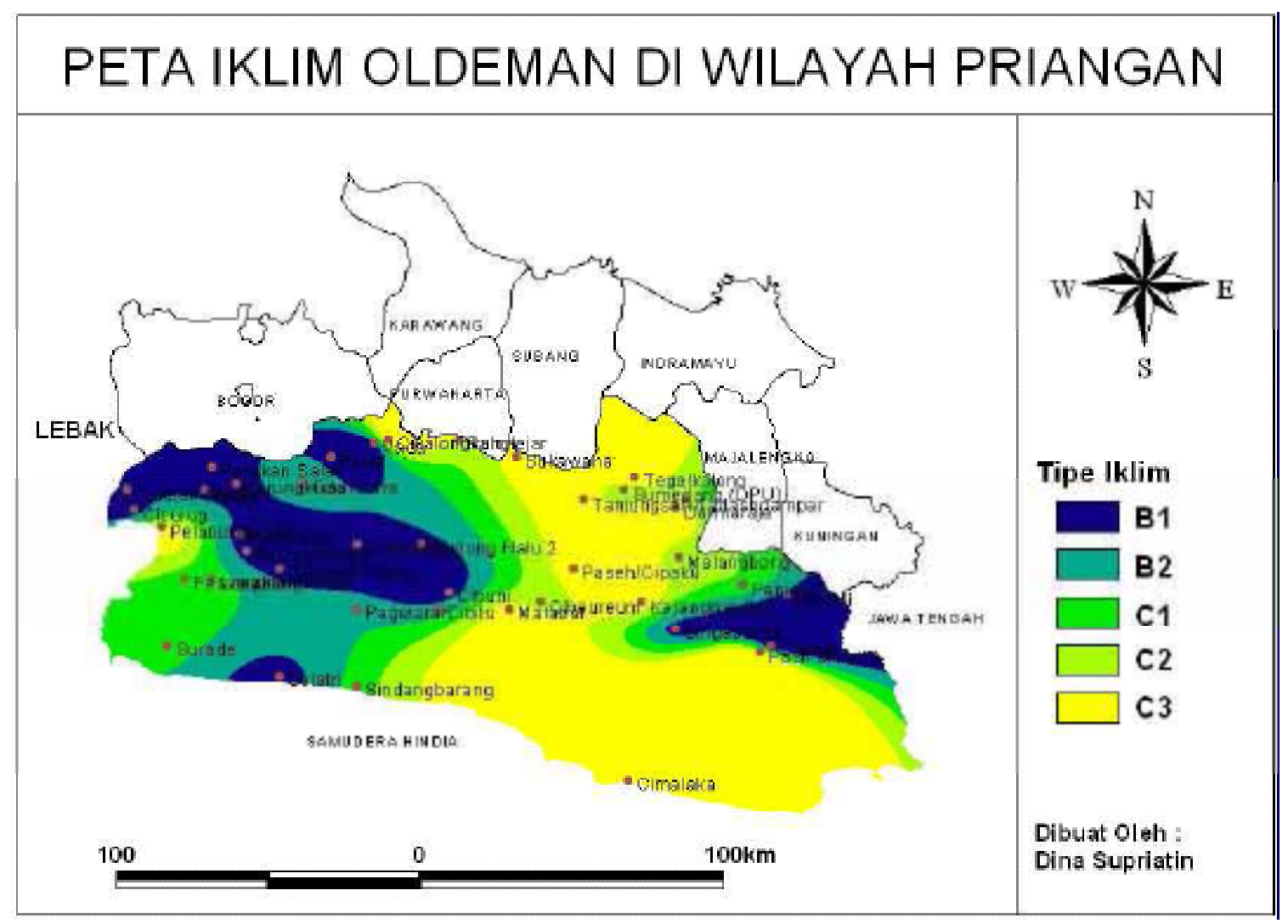

Gambar 2. Hasil Pemetaan Tipe Iklim di Wilayah Priangan Berdasarkan Oldeman

Berdasarkan hasil pengolahan dan analisa data curah hujan bulanan periode 30 tahun (1971-2000) untuk wilayah Priangan dari 41 pos hujan (Tabe 2) maka diperoleh tipe iklim menurut Oldeman untuk masing-masing pos hujan adalah sebagai berikut,

\section{Tipe B1}

Menurut Oldeman, tipe iklim B1 adalah tipe iklim dengan kriteria jumlah bulan basah 7-9 dan jumlah bulan kering <2. Daerah dengan tipeiklim ini adalah Parakan Salak, Parungkuda, Cisalak, Cicurug, Cipetir, Mandaling, Pacet, Bojonglopang, Dinewati, Vada, Campaka, Salatri, Gunung Halu2, Cibuni, Singaparna, Kawali dan Ciamis. Daerah dengan tipe iklim ini merupakan daerah yang sangat basah karena tingginya curah hujan yang turun di wilayah tersebut serta didukung oleh kondisi topografinya yang terletak di dataran tinggi seperti daerah Parakan Salak, Parungkuda, Cisal ak, Cicurug, Cipetir, Mandaling, Pacet, Bojonglopang, Dinewati, Vada, Campaka, Gunung Halu2, Cibuni, Singaparna, Kawali dan Ciamis. Untuk daerah yang terletak di dataran rendah yaitu Salatri, tingginya curah hujan yang turun di daerah ini dipengaruhi oleh kondisi lokal di daerah tersebut. A pabila dilihat dari letak geografisnya sebelah Selatan berbatasan dengan Samudera Hindia dan sebelah Barat berbatasan dengan Sungai Cibuni sehingga faktor konveksi sangat berpengaruh terhadap proses terjadinya hujan di daerah ini. Menurut zona agroklimat Oldeman untuk daerah dengan tipe iklim B1 memiliki sistem 
pola tanam 3PS atau 2PS + 1 PL. Yaitu dalam setahun daerah dengan tipe iklim B1 dapat ditanami 3 (tiga) kali padi sawah berumur pendek atau dalam setahun dapat ditanami 2 (dua) kali padi sawah berumur pendek dimana diantara kedua masa tanam padi sawah itu dapat ditanami 1 (satu) kali palawija.

\section{Tipe B2}

Menurut Oldeman, tipe iklim B2 adalah tipe iklim dengan kriteria jumlah bulan basah 7-9 dan jumlah bulan kering 2-3. Daerah dengan tipe iklim ini adalah Goal Para, Pagelaran dan Cibitu. Daerah dengan tipe iklim ini merupakan daerah yang sangat basah karena tingginya curah hujan yang turun di wilayah tersebut serta didukung oleh kondisi topografinya yang terletak di dataran tinggi. Selain itu apabiladilihat dari letak geografisnya daerah dengan tipeiklimini terletak di daerah al iran sungai (DAS), sehingga faktor konveksi sangat berpengaruh terhadap proses terjadinya hujan di daerah ini. Menurut zona agroklimat Oldeman untuk daerah dengan tipe iklim B2 memiliki sistem pola tanam 2PS + 1PL. Yaitu dalam setahun daerah dengan tipe iklim B2 dapat ditanami 2 (dua) kali padi sawah berumur pendek dimana diantara kedua masa tanam padi sawah itu dapat ditanami 1 (satu) kali palawija.

\section{Tipe C 1}

Menurut Oldeman, tipe iklim $\mathrm{C} 1$ adalah tipe iklim dengan kriteria jumlah bulan basah 5-6 dan jumlah bulan kering $<2$. Daerah dengan tipe iklim ini adalah Pesawahan, Surade, Lengkong, Sindangbarang dan Panjalu. Daerah dengan tipe iklim ini merupakan daerah dengan curah hujan yang cukup tinggi. A pabila dilihat dari letak geografisnya daerah dengan tipe iklim ini terletak di bagian Selatan Jawa Barat yang berbatasan langsung dengan Samudera Hindia sehingga faktor konveksi sangat berpengaruh terhadap proses terjadinya hujan di daerah ini. Menurut zona agroklimat Oldeman untuk daerah dengan tipe iklim C1 memiliki sistem pola tanam 1PS +2PL. Yaitu dalam setahun daerah dengan tipe iklim C1 setahun dapat ditanami 2 (dua) kali palawija dimana diantara kedua masa tanam palawija itu dapat ditanami 1 (satu) kali padi sawah.

\section{Tipe C2}

Menurut Oldeman, tipe iklim C2 adalah tipe iklim dengan kriteria jumlah bulan basah 5-6 dan jumlah bulan kering 2-3. Daerah dengan tipe iklim ini adalah Panglejar, Cibeureum, Sumedang, Cadasngampar dan Malangbong. Daerah dengan tipe iklim ini merupakan daerah dengan curah hujan yang cukup tinggi. A pabila dilihat dari peta topografinya daerah dengan tipeiklim ini berada di daerah landai, faktor orografis sangat berpengaruh terhadap proses terjadinya hujan di daerah ini. Menurut zona agroklimat Oldeman untuk daerah dengan tipe iklim C2 memiliki sistem pola tanam 1PS +1PL +1SK. Yaitu dalam setahun daerah dengan tipeiklim C2 dan C3 dapat ditanami 1 (satu) kali padi sawah dan 1 (satu) kali palawija dengan syarat untuk masa tanam yang kedua tidak jatuh pada musim kemarau.

\section{Tipe C3}

Menurut Oldeman, tipe iklim C3 adalah tipe iklim dengan kriteria jumlah bulan basah 5-6 dan jumlah bulan kering 4-6. Daerah dengan tipe iklim ini adalah Pelabuhan Ratu, Cikalongkulon, Sukawana, Paseh/ Cipaku, Malabar, Cimalaka, 
Darmaraja, Karangpawitan, Tegalkalong, Pasir Malang dan Tanjungsari1. Daerah dengan tipe iklim ini merupakan daerah dengan curah hujan yang cukup tinggi. A pabila dilihat dari peta topografinya daerah dengan tipe iklim ini berada di daerah landai, faktor orografis sangat berpengaruh terhadap proses terjadinya hujan di daerah ini. Menurut zona agroklimat Oldeman untuk daerah dengan tipe iklim C3 memiliki sistem pola tanam 1PS +1PL +1SK. Yaitu dalam setahun daerah dengan tipe iklim C2 dan C3 dapat ditanami 1 (satu) kali padi sawah dan 1 (satu) kali palawija dengan syarat untuk masa tanam yang kedua tidak jatuh pada musim kemarau. Berdasarkan hasil analisa dan pemabahasan di atas, sistem pola tanam di wilayah Priangan dapat dilihat seperti pada tabel 3.

Tabel 3. Hasil Pengelompokkan Kecamatan

Berdasarkan Tipe Iklim Oldeman dan Pola Tanam

\begin{tabular}{|c|c|c|c|}
\hline No & $\begin{array}{l}\text { Tipe iklim } \\
\text { Oldeman }\end{array}$ & Pola Tanam & Kecamatan \\
\hline 1 & B1 & 3PS atau $2 \mathrm{PS}+1 \mathrm{PL}$ & $\begin{array}{l}\text { Parakan Salak, Parungkuda, Cisalak, } \\
\text { Cicurug, Cipetir, Mandaling, Pacet, } \\
\text { Bojonglopang, Dinewati, Vada, } \\
\text { Campaka, Salatri, Gunung Halu2, } \\
\text { Cibuni, Singaparna, Kawali dan } \\
\text { Ciamis. }\end{array}$ \\
\hline 2 & B2 & $2 \mathrm{PS}+1 \mathrm{PL}$ & Goal Para, Pagelaran dan Cibitu. \\
\hline 3 & $\mathrm{C} 1$ & $1 \mathrm{PS}+2 \mathrm{PL}$ & $\begin{array}{l}\text { Pesawahan, Surade, Lengkong, } \\
\text { Sindangbarang dan Panjalu. }\end{array}$ \\
\hline 4 & $\mathrm{C} 2$ dan $\mathrm{C} 3$ & $1 \mathrm{PS}+1 \mathrm{PL}+1 \mathrm{SK}$ & $\begin{array}{l}\text { Panglejar, Cibeureum, Sumedang, } \\
\text { Cadasngampar, Malangbong, } \\
\text { Pelabuhan Ratu, Cikalongkulon, } \\
\text { Sukawana, Paseh/Cipaku, Malabar, } \\
\text { Cimalaka, Darmaraja, Karangpawitan, } \\
\text { Tegalkalong, Pasir Malang dan Tj. Sari } \\
\text { Tanjungsaari } 1 .\end{array}$ \\
\hline
\end{tabular}

\section{SIMPULAN}

Berdasarkan hasil pengolahan dan analisa data curah hujan bulanan dari 41 pos hujan di wilayah Priangan maka dapat disimpulkan bahwa berdasarkan klasifikasi iklim Oldeman diperoleh 5 tipe iklim di wilayah Priangan yaitu: B1, B2, C1, C2 dan C3. Tipeiklim paling basah di wilayah Priangan adalah tipeiklim B1 dengan jumlah bulan basahnya 7-9 dan jumlah bulan keringnya $<2$ yang berada di daerah Parakan Salak, Parungkuda, Cisalak, Cicurug, Cipetir, Mandaling, Pacet, Bojonglopang, Dinewati, Vada, Campaka, Salatri, Gunung Halu, Cibuni, Singaparna, Kawali dan Ciamis. Yang cocok ditanami padi sawah umur pendek 3 (tiga) kali panen atau padi sawah umur pendek 2 (dua) kali panen dan palawija 1 (sastu) kali panen. Tipe iklim paling kering di wilayah Priangan adalah tipe iklim C3 dengan jumlah bulan basah 5-6 dan jumlah 
bulan kering 4-6 yang berada di daerah Pelabuhan Ratu, Cikalongkulon, Sukawana, Paseh/ Cipaku, Malabar, Cimalaka, Darmaraja, Karangpawitan, Tegalkalong, Pasir Malang dan Tanjungsaril. Yang cocok ditanami padi sawah umur pendek 1 (satu) kali panen dan palawija 2 (dua) kali panen khusus yang kedua jatuh pada musim kemarau. Keadaan topografi suatu daerah sangat berpengaruh terhadap kondisi iklim daerah tersebut.

\section{DAFTAR PUSTAKA}

Hadiyanto, S. (2007). Pola Tingkat Kerawanan Kekeringan Di Jawa Tengah. Program Pasca Sarjana IImu Geografi. Universitas Indonesia. Depok.

Komarudin, N., Koswara, dan Sulistyawati. (2006). Klasifikasi Iklim Menuruut Oldeman untuk wilayah Semarang, Jurnal M eteorologi dan Geofisika Vol. 7. No.1, Edisi Maret 2006, hal 82-87. Badan Meteorologi dan Geofisika, Jakarta.

Lakitan, B., (1994). D asar-D asar K limatologi. Raja Grafindo Persada. Jakarta.

Nurdin, H. (2001). Panduan M enggunakan A rcV iew 3.2 dan A plikasinya dalam Bidang Iklim dan Cuaca. In W orkshop Climatology Station Kediri-W est N usa Tenggara. Lombok.

Oldeman L.R. dan M. Frere, (1982). A Study of the A groclimatology of the H umid Tropics of South-east A sia. WMO Interagency Project on Agroclimatology.

Prawirowardoyo, S. (1996). M eteorologi U mum. Institut Teknologi Bandung, Bandung. Soenardi. (2008). Klasifikasi I klim M enurut OIdeman O Ideman di Yogyakarta. Program Diploma III M eteorologi. A kademi Meteorologi dan Geofisika, Jakarta.

Spiegel, M.R., Susila, I.N., dan Gunawan, E. (1992). Teori dan Soal-soal Statistik V ersi SI (M etrik). Erlangga, Jakarta.

Tjasyono, B. (1992). Klimatologi Terapan. Institut Teknologi Bandung, Bandung.

Tjasyono, B. (1999). Klimatologi U mum. Institut Teknologi Bandung, Bandung.

Tjasyono, B. (2004). K limatologi . Institut Teknologi Bandung, Bandung.

Utoyo, B. (2007). Geografi M embuka Cakrawala D unia untuk Kelas XI Sekolah M enengah A tas/M adrasah Aliyah Program IImu Pengetahuan Sosial. Raja Grafindo Persada, Jakarta.

Klasifikasi Iklim menurut Oldeman. www.klimatologibanjarbaru.com. A kses tanggal 10 November 2009.

Klasifikasi Iklim Oldeman. http:/ / bumikupijak.com. Akses tanggal 13 November 2009.

Klasifikasi Iklim. www.diknum.go.id. A kses tanggal 13 November 2009.

Pertanian di Indonesia. www.indonesia.go.id. A kses tanggal 22 November 2009.

Pertanian di Jawa Barat. www.jabar.go.id. A kses tanggal 22 N ovember 2009. 